
Horticultura Brasileira 27: 155-159.

\title{
Cultivo de híbridos de pimentão amarelo em fibra da casca de coco
}

\author{
Hamilton César de O Charlo; Renata Castoldi; Carolina Fernandes; Pablo F Vargas; Leila T Braz \\ UNESP-FCAV, Dep ${ }^{\text {to }}$ Prod. Vegetal, Rodov. Prof. Paulo Donato Castellane s/n, 14884-900 Jaboticabal-SP; hamiltoncharlo@ gmail.com
}

\begin{abstract}
RESUMO
Objetivou-se avaliar a produtividade de cinco híbridos de pimentão amarelo em ambiente protegido, utilizando fibra de casca de coco e fertirrigação. Adotou-se o delineamento em blocos casualizados, com cinco cultivares (Zarco, CLXP 1463, Línea, Matador e Eppo), e quatro repetições, sendo cada parcela constituída por onze plantas. O cultivo de pimentão foi feito em sistema aberto em vasos plásticos de $13 \mathrm{~L}$, transplantando-se uma muda por vaso, as quais foram produzidas em bandejas de poliestireno expandido. Adotou-se o espaçamento de $0,8 \mathrm{~m}$ entre fileiras simples, $1,10 \mathrm{~m}$ entre fileiras duplas e $0,5 \mathrm{~m}$ entre plantas. As plantas foram conduzidas com quatro hastes principais e tutoradas individualmente em forma de "V". A colheita dos frutos foi realizada quando estes atingiam o tamanho ideal e, no mínimo, $70 \%$ da coloração amarela. Avaliaram-se o comprimento e o diâmetro médio dos frutos, a relação comprimento/diâmetro, a espessura da polpa, o teor de sólidos solúveis totais, o $\mathrm{pH}$, o número de frutos por planta, a massa total de frutos por planta, o peso médio dos frutos, a produtividade total e comercial, e a classificação dos frutos. O híbrido CLXP 1463 produziu frutos de maior comprimento e diâmetro. Este híbrido apresentou menor número de frutos por planta, porém com maior massa. Para as características espessura da polpa, sólidos solúveis totais e $\mathrm{pH}$ não se verificou diferença significativa entre os híbridos. Os híbridos CLXP 1463, Eppo e Matador se mostraram promissores, com produtividades comerciais de 107,61; 102,62 e 95,31 tha ${ }^{-1}$, respectivamente. Os híbridos CLXP 1463, Eppo, Línea e Matador apresentaram toda a produção classificada como Extra.
\end{abstract}

Palavras-chave: Capsicum annuum, produtividade, substrato.

\begin{abstract}
Performance of yellow sweet peppers hybrids grown in coconut husk fiber

The yield of five yellow sweet pepper hybrids was evaluated in protected cultivation, using coconut fiber and fertirrigation. The experiment was arranged in a randomized blocks design, with five cultivars (Zarco, CLX 1463, Línea, Matador and Eppo) and four replications, therefore each plot comprised eleven plants. Plants were grown in open system, in plastic pots of $13 \mathrm{~L}$, transplanting one seedling pot, which was produced in polystyrene trays. The spacing utilized was single row spacing of $0.8 \mathrm{~m}$, double rows of $1.10 \mathrm{~m}$ and plant spacing of $0.5 \mathrm{~m}$. The plants were trained individually in "V" shape with four main stems. Fruits were harvested at ideal size, with at least $70 \%$ of the skin yellow colored. There were studied: fruit mean length and diameter, the ratio length/diameter, pulp thickness, total soluble solids content, $\mathrm{pH}$, number of fruits per plant, total weight of fruits per plant, mean fruit weight, total and commercial yield and fruit classification. The hybrid CLXP 1463 yielded fruits of greater length and diameter. This hybrid produced lower number of fruit per plant, but with greater mass. For the characteristics of pulp thickness, total soluble solids and $\mathrm{pH}$ there was not significant difference between hybrids. The hybrids CLXP 1463, Eppo and Matador showed themselves to be promising, with commercial yields of 107.61, 102.62 and $95.31 \mathrm{tha}^{-1}$, respectively. The whole production of the hybrids CLXP 1463, Eppo, Línea and Matador was classified as Extra.
\end{abstract}

Keywords: Capsicum annuum, yield, substrate.

(Recebido para publicação em 27 de março de 2008; aceito em 13 de maio de 2009) (Received in March 27, 2008; accepted in May 13, 2009)

$\mathrm{O}$ pimentão é uma das espécies do grupo das hortaliças mais difundidas e consumidas no Brasil na forma in natura, sendo considerada uma das dez espécies de maior importância econômica no mercado de hortaliças (Ribeiro et al., 2000). Sua produção está concentrada principalmente no estado de São Paulo, maior produtor com 8.291 hectares, produzindo 70 mil toneladas e gerando 4.543 empregos (Marchizeli et al., 2003). A crescente demanda do produto no País tem ampliado seu cultivo em casa de vegetação, devido à maior segurança na produção, reduzindo perdas e conseqüentemente, aumento do rendimento e da qualidade dos frutos.

Atualmente, não existem cultivares de pimentão resistentes a $M$. incognita e $M$. mayaguensis, o que provoca uma intensa mudança de áreas de cultivo, ou a necessidade de tratamento de solo, causando grandes impactos ambientais. Uma possível saída para este problema é o cultivo em vasos ou sacos ("bags"), preenchidos com substratos.

O cultivo em substratos com a utilização de fertirrigação promove o incremento de produtividade e da qualidade dos frutos produzidos, por fornecer às plantas quantidade de nutrientes adequada para cada estádio de desenvolvimento da cultura. Neste contexto, o aproveitamento da casca do coco surge como boa alternativa, tanto na área agrícola como florestal, por ser um produto renovável e ecologicamente correto.

Vale ressaltar que a condução das plantas se torna mais fácil no sistema de cultivo em vasos contendo substratos, pois as plantas desenvolvem seu sistema radicular normalmente, e assim ficam fixas, não sendo arrancadas por ocasião de ventanias, como pode ocorrer em cultivo hidropônico sem substrato.

Outro fator importante que difere o cultivo do pimentão em vasos do sistema de hidroponia sem substrato, é a menor dependência de constantes irrigações, pois o substrato funciona como um reservatório de água e nutrientes às plantas, vantagem esta que não se observa no cultivo hidropônico.

Carrijo et al. (2004), avaliando a produção das cultivares de tomate Larissa e TX em diferentes substratos, verificaram que as maiores produtividades foram obtidas no substrato feito a partir 
da fibra da casca de coco $\left(10,4 \mathrm{~kg} \mathrm{~m}^{-2}\right)$.

Por ser uma técnica de cultivo recente, são escassos na literatura trabalhos apresentando dados de produtividade, bem como a indicação de híbridos de pimentão mais produtivos, quando estes são cultivados em substratos, acondicionados em vasos, com fertirrigação. Portanto, a avaliação de novas cultivares, aliada ao emprego de modernas técnicas de cultivo, como por exemplo o cultivo em fibra da casca de coco, se faz de suma importância, pois a produção é o resultado da interação de genótipos $\mathrm{x}$ ambientes.

Este trabalho teve por objetivo avaliar a produtividade de cinco híbridos de pimentão amarelo em ambiente protegido, cultivados em fibra de casca de coco e fertirrigados.

\section{MATERIAL E MÉTODOS}

O experimento foi conduzido em casa de vegetação construída em estrutura metálica, do tipo teto em arco com $3 \mathrm{~m}$ de pé-direito, coberta com filme de polietileno transparente, aditivado contra raios ultravioleta, com 150 micrômetros de espessura, e as laterais protegidas com telas de polipropileno preto com $50 \%$ de sombreamento, na UNESP em Jaboticabal-SP, de 14 de dezembro de 2004 a 18 de junho de 2005 . O clima, segundo a classificação de Köppen, é do tipo Aw com transição para Cwa (Volpe ${ }^{1}$ ).

O delineamento experimental adotado foi de blocos casualizados, com cinco tratamentos (híbridos Zarco, Matador, Eppo, Línea e CLXP 1463) e quatro repetições. Cada parcela constou de onze plantas, sendo avaliadas as nove plantas centrais.

As mudas foram produzidas em bandejas de poliestireno expandido, com capacidade para 128 células piramidais, colocando-se uma semente por célula, utilizando como substrato o Plantmax Hortaliças ${ }^{\circledR}$ tipo HT, acondicionadas em ambiente protegido, recebendo irrigação por aspersão 3 ou 4 vezes ao dia. Aos 30 dias após a semeadura, as mudas foram transplantadas para copos plásticos de
$300 \mathrm{~mL}$, perfurados no fundo, utilizando substrato Plantmax Hortaliças® tipo HT, onde ficaram por mais 10 dias para garantir melhor enraizamento.

O cultivo do pimentão foi realizado em regime de hidroponia aberta (sem circulação da solução nutritiva) e em vasos plásticos de $13 \mathrm{~L}$. Os vasos foram preenchidos com fibra da casca de coco, previamente umedecida, e dispostos em fileiras duplas, nos espaçamentos $0,8 \mathrm{~m}$ entre fileiras simples, $1,10 \mathrm{~m}$ entre fileiras duplas e $0,5 \mathrm{~m}$ entre plantas na fileira. Em cada um desses recipientes, foi transplantada uma muda de pimentão, com 40 dias de idade, apresentando de 6 a 8 folhas definitivas e aproximadamente $12 \mathrm{~cm}$ de altura.

A fertirrigação foi realizada constantemente, ou seja, os fertilizantes foram aplicados em todas as irrigações. O método de irrigação adotado foi o localizado, do tipo gotejamento, com a utilização de emissores com vazão de 14 mL/ min, sendo colocados dois emissores em cada recipiente. Semanalmente foi determinado o volume da solução nutritiva aplicado na fertirrigação. Para tanto era aplicada solução nutritiva até atingir a capacidade de vaso e iniciar a lixiviação. Imediatamente quando se iniciava a lixiviação, a irrigação era cessada, e o volume de água gasto era definido como o volume a ser aplicado durante aquela semana, de maneira a promover a drenagem mínima dos vasos e garantir a uniformidade na distribuição de água no substrato acondicionado no vaso.

Foi adotada a solução nutritiva recomendada por Goto \& Rossi (1997), citados por Trani \& Carrijo (2004), para a cultura do pimentão. Para o preparo de 100 L da solução foram utilizados nitrato de cálcio $(650 \mathrm{~g})$, nitrato de potássio (500 g), fosfato monopotássico - MKP$(170 \mathrm{~g})$, sulfato de magnésio $(250 \mathrm{~g})$, nitrato de magnésio (50 g), ferro-EDTA (11 $\mathrm{g}$ de cloreto de ferro $+15 \mathrm{~g}$ de EDTA dissódico) e $150 \mathrm{~mL}$ da solução estoque de micronutrientes. Esta solução estoque de micronutrientes era preparada com 16,70 g de acido bórico, $15 \mathrm{~g}$ de cloreto de manganês, $0,82 \mathrm{~g}$ de cloreto de cobre, 0,33 g de óxido de molibidêdino e 2,62 g de sulfato de zinco diluídos em 1L de água.

As plantas foram conduzidas em forma de "V, com quatro hastes principais e tutoradas de forma individual com fitilhos plásticos presos a fios de aço que se encontravam a 2,2 $\mathrm{m}$ de altura no ambiente protegido, e estendidos sobre todas as linhas de cultivo e fixados a suportes de madeira. As flores que surgiram na primeira bifurcação foram retiradas. Durante todo o cultivo, foram feitas desbrotas dos brotos laterais com auxílio de bisturi cirúrgico, garantindo que cada planta ficasse com apenas quatro hastes. Para a fixação das plantas nos fitilhos, foi utilizado alceador de maneira a evitar o tombamento da planta e a quebra das hastes, devido ao peso dos frutos à medida que as plantas foram crescendo.

O controle de pragas e de doenças foi realizado adotando-se o um manejo racional, no qual se efetuou a aplicação de agrotóxicos mediante, a constatação visual do agente, inseto ou patógeno.

Em 07 de março de 2005, observaram-se, nos frutos, sintomas de podridão apical, provocados pela deficiência de cálcio, devido, provavelmente, às altas temperaturas registradas dentro da casa de vegetação, que dificultam a translocação deste elemento para os frutos. Os frutos que apresentavam os sintomas foram retirados das plantas e descartados.

A partir desta data, foram realizadas semanalmente aplicações foliares de nitrato de cálcio, na dose de 10 gramas/L, com pulverizador costal, com jato direcionado aos frutos.

A colheita foi iniciada aos 84 dias após o transplante, quando os frutos apresentavam pelo menos $70 \%$ de sua superfície de cor amarela e estendendose até aos 148 dias após o transplante. Os frutos colhidos foram conduzidos ao laboratório, onde avaliaram-se o comprimento médio dos frutos, o diâmetro médio dos frutos, a relação comprimento/ diâmetro, espessura média da polpa dos frutos, teor de sólidos solúveis totais, potencial hidrogeniônico $(\mathrm{pH})$, número de frutos por planta, produção total por

${ }^{1}$ VOLPE CA. 2005. (Faculdade de Ciências Agrárias e Veterinárias, UNESP - Câmpus de Jaboticabal) Comunicação pessoal. 
planta, massa fresca média dos frutos, produtividade total e comercial (expressas em t ha-1) e a classificação dos frutos. Para a determinação da produtividade total foram considerados a produção por planta e o número estimado de plantas por hectare (25.000 plantas). Já para o cálculo da produtividade comercial, foram desconsiderados os frutos que apresentavam defeitos graves.

Para a classificação dos frutos, foram levados em consideração o grupo, o subgrupo, a classe, a subclasse e a categoria, seguindo recomendações de São Paulo (1998), a partir das medidas de comprimento e diâmetro dos mesmos, as quais fornecem a classe e a subclasse, respectivamente. Fizeram-se também as identificações do formato e da coloração dos frutos, as quais fornecem o grupo e o subgrupo, respectivamente.

A identificação da qualidade foi feita pela caracterização e quantificação dos defeitos considerados graves e leves. Portanto, a categoria dos frutos de pimentão obedecem aos limites de tolerância desses defeitos, permitindo a classificação em Extra, Categoria I, Categoria II e Categoria III, conforme a legislação do programa paulista para melhoria dos padrões comerciais de hortaliças do Ceagesp (São Paulo, 1998).

Os dados obtidos foram submetidos à análise de variância e as médias foram comparadas pelo teste de Tukey.

\section{RESULTADOS E DISCUSSÃO}

Verificou-se diferenças significativas entre os tratamentos para o comprimento, diâmetro de frutos e relação comprimento/diâmetro (Tabela 1). O híbrido CLXP 1463 apresentou a maior média para o comprimento $(13,60 \mathrm{~cm})$, não diferindo estatisticamente apenas do híbrido Matador $(12,30 \mathrm{~cm})$. Línea foi o híbrido com a menor média de comprimento de frutos $(10,60 \mathrm{~cm})$. Silva et al. (2005a) em sistema hidropônico NFT, verificaram que o híbrido Matador destacou-se entre vários genótipos com relação ao comprimento de frutos.

O híbrido CLXP 1463 produziu frutos com maior diâmetro $(7,89 \mathrm{~cm})$, porém não diferiram significativamente dos

Tabela 1. Médias do comprimento e diâmetro do fruto, relação comprimento/diâmetro e da espessura da polpa de cinco híbridos de pimentão amarelo, cultivados em fibra da casca de coco com fertirrigação, em ambiente protegido (Means of length and diameter of the fruit, length/diameter ratio and thickness of the pulp of five hybrids of yellow bell pepper, grown in coconut husk fiber with fertirrigation, in protected environment). Jaboticabal, UNESPFCAV, 2005.

\begin{tabular}{lcccc}
\hline Híbrido & $\begin{array}{c}\text { Comprimento } \\
(\mathbf{c m})\end{array}$ & Diâmetro (cm) & $\begin{array}{c}\text { Relação } \\
\text { comp./diâm. }\end{array}$ & $\begin{array}{c}\text { Espessura da } \\
\text { polpa }(\mathbf{m m})\end{array}$ \\
\hline CLXP 1463 & $13,60 \mathrm{a}$ & $7,89 \mathrm{a}$ & $1,76 \mathrm{bc}$ & $6,43 \mathrm{a}$ \\
Zarco & $12,07 \mathrm{~b}$ & $6,42 \mathrm{c}$ & $2,07 \mathrm{a}$ & $5,23 \mathrm{a}$ \\
Eppo & $11,05 \mathrm{bc}$ & $7,54 \mathrm{ab}$ & $1,54 \mathrm{c}$ & $5,97 \mathrm{a}$ \\
Línea & $10,60 \mathrm{c}$ & $7,53 \mathrm{ab}$ & $1,53 \mathrm{c}$ & $6,04 \mathrm{a}$ \\
Matador & $12,30 \mathrm{ab}$ & $7,05 \mathrm{bc}$ & $1,93 \mathrm{ab}$ & $6,05 \mathrm{a}$ \\
\hline CV (\%) & 5,10 & 4,16 & 7,13 & 18,76 \\
\hline
\end{tabular}

Médias seguidas pela mesma letra na coluna não diferem entre si, pelo teste de Tukey, a 5\% de probabilidade (means followed by the same letter in the column do not differ significantly, according to Tukey's test at 5\% level of probability).

híbridos Eppo e Línea. O híbrido Zarco produziu frutos com menor diâmetro (Tabela 1). Estes resultados são semelhantes aos observados por Silva et al. (2005b), para Matador e Zarco, cultivados em solo sob ambiente protegido, em cultivo convencional.

Para a relação comprimento/diâmetro o híbrido Zarco apresentou o maior valor, embora não tenha diferido do híbrido Matador. Esta relação está ligada ao formato do fruto, sendo que os frutos de formato quadrado, também chamados de "block", apresentam relação comprimento/diâmetro mais próxima de 1. Frutos mais alongados, sejam eles dos grupos retangular ou cônico, apresentam relação mais distante de 1 . Atualmente os consumidores têm preferência por frutos de formato quadrado, portanto os frutos dos híbridos Eppo, Línea e CLXP 1463 têm maior aceitação no comércio.

Observou-se que, para espessura de polpa, não houve diferença significativa entre os tratamentos, com média de 6,01 mm (Tabela 1). Frizzone et al. (2005), em seus estudos com a cultura do pimentão do subgrupo amarelo, verificaram médias inferiores de espessura de polpa, variando de 2,5 a 5,6 $\mathrm{mm}$. Vale ressaltar que frutos que apresentam polpa mais espessa, são mais resistentes ao transporte, têm maior duração pós-colheita e maior rendimento em massa, além de sua maior preferência pelo mercado.
Para todas as características apresentadas na Tabela 2, com exceção do teor de sólidos solúveis totais, detectou-se diferença estatística significativa entre os híbridos avaliados.

Os valores de sólidos solúveis totais variaram de 5,85 a 7,42, embora não tenha se observado diferenças significativas entre os híbridos para esta característica. Rocha et al. (2004), avaliando as características químicas de frutos de híbridos de pimentão, observaram valores de sólidos solúveis totais ( ${ }^{\circ}$ Brix) variando de 4,39 a 4,96.

O híbrido Zarco apresentou a menor média de $\mathrm{pH}(4,98)$; sendo portanto seus frutos, mais ácidos que os demais. $\mathrm{Na}$ presente pesquisa, os valores de $\mathrm{pH}$ variaram de 4,98 até 5,26. Estes valores estão próximos aos observados por Factor (2003), que verificou em frutos maduros de pimentão da cultivar Margarita, cultivada em diferentes substratos e soluções nutritivas, valores de $\mathrm{pH}$ na faixa de 4,95 a 5,04.

O híbrido Zarco apresentou maior número de frutos por planta $(21,64)$. No entanto, a produção por planta foi maior no híbrido CLXP 1463. A cultivar CLXP 1463 produz frutos com maior massa, como pode ser observado na Tabela 2.

Silva et al. (2005a), avaliando a produtividade de cultivares de pimentão em 
Tabela 2. Médias de teor de sólidos solúveis totais (SST) e do pH da polpa, do número de frutos por planta, produção por planta, massa média dos frutos, produtividade total e produtividade comercial de cinco híbridos de pimentão amarelo, cultivados em fibra da casca de coco com fertirrigação, em ambiente protegido (means of total soluble solids (SST), pH, number of fruit per plant, production per plant, mean weight of fruit, total yield and commercial yield estimated of five hybrids of yellow bell pepper, grown in coconut husk fiber with fertirrigation, in a protected environment.). Jaboticabal, UNESP-FCAV, 2005.

\begin{tabular}{|c|c|c|c|c|c|c|c|}
\hline Híbrido & SST ( ${ }^{\circ}$ Brix) & $\mathrm{pH}$ & $\begin{array}{c}\mathrm{N}^{\circ} \\
\text { frutos/planta }\end{array}$ & $\begin{array}{l}\text { Produção/ } \\
\text { planta (kg) }\end{array}$ & $\begin{array}{l}\text { Massa média } \\
\text { dos frutos(g) }\end{array}$ & $\begin{array}{c}\text { Produtividade } \\
\text { total }\end{array}$ & $\begin{array}{c}\text { Produtividade } \\
\text { comercial }\end{array}$ \\
\hline CLXP 1463 & $6,55 \mathrm{a}$ & $5,26 a$ & $16,94 \mathrm{~b}$ & $4,32 \mathrm{a}$ & 257,25 a & $108,17 \mathrm{a}$ & $107,61 \mathrm{a}$ \\
\hline Zarco & $7,42 \mathrm{a}$ & $4,98 \mathrm{~b}$ & $21,64 \mathrm{a}$ & $3,66 \mathrm{bc}$ & $170,00 \mathrm{c}$ & $91,60 \mathrm{bc}$ & $91,50 \mathrm{~b}$ \\
\hline Eppo & $5,85 a$ & $5,07 a b$ & $18,39 a b$ & $4,12 a b$ & $223,75 b$ & $102,90 a b$ & $102,62 a b$ \\
\hline Línea & $6,37 \mathrm{a}$ & $5,15 a b$ & $19,66 \mathrm{ab}$ & $3,55 \mathrm{c}$ & $181,75 \mathrm{c}$ & $88,87 \mathrm{c}$ & $88,75 b$ \\
\hline Matador & $6,62 \mathrm{a}$ & $5,06 a b$ & $20,78 \mathrm{ab}$ & $3,81 \mathrm{abc}$ & $184,00 \mathrm{c}$ & $95,40 \mathrm{abc}$ & $95,31 \mathrm{ab}$ \\
\hline CV (\%) & 12,69 & 2,07 & 9,10 & 6,35 & 5,97 & 6,33 & 6,52 \\
\hline
\end{tabular}

Médias seguidas pela mesma letra na coluna não diferem entre si, pelo teste de Tukey, a 5\% de probabilidade (means followed by the same letter in the column do not differ significantly, according to Tukey's test at 5\% level of probability).

hidroponia, observaram para as cultivares Zarco e Matador 17,75 e 31,25 frutos por planta, respectivamente. Comparando-se os resultados, nota-se uma diferença significativa entre o número de frutos obtidos na presente pesquisa e os observados pelos referidos autores para o híbrido Matador. Porém a produção por planta foi semelhante nos dois trabalhos, sendo que Silva et al. (2005a) obtiveram $4,12 \mathrm{~kg}$ planta $^{-1}$, não relatando o tempo de colheita do experimento, enquanto, no presente trabalho, em dois meses de colheita, foram observados $3,81 \mathrm{~kg}$ planta $^{-1}$.

Verificou-se diferença significativa entre os tratamentos para produtividade total e comercial (Tabela 2). As produtividades comerciais variaram de 9,14 a $10,76 \mathrm{~kg} \mathrm{~m}^{-2}$, sendo que a cultivar CLXP 1463 apresentou maior produção comercial, com 10,76 $\mathrm{kg} \mathrm{m}^{-2}$, embora não tenha diferido dos híbridos Eppo e Matador.

A produção de pimentão em casa de vegetação obtida pelos produtores associados de Reginóplis e região (PARE), em dois meses de colheita, é de aproximadamente de 35 t/ha (Ferraz, 2005²).

De maneira geral, os rendimentos médios obtidos no presente trabalho superam a maioria dos encontrados na literatura (Factor, 2003; Pereira, 1995; Rosa, 1995; Queiroga et al., 2002; Fontes et al., 2005). Portanto, a produção de pimentão em recipientes sob ambiente protegido, utilizando fibra da casca de coco e fertirrigação, mostrou-se uma técnica muito promissora, visto que as produtividades observadas são elevadas.

Para a classificação dos frutos verificou-se que os híbridos CLXP 1463,
Eppo e Línea pertencem ao grupo (formato) quadrado, e os demais, ao grupo retangular. Quanto ao subgrupo (coloração), todos os híbridos avaliados são do subgrupo amarelo. Para a classe (comprimento), os híbridos CLXP 1463, Zarco e Matador produziram frutos que se enquadram na classe 12 (12 a 15 cm de comprimento). Os híbridos Eppo e Línea foram classificados na classe 10 (10 a 12 $\mathrm{cm}$ de comprimento). Para a subclasse, todos os foram classificados na subclasse 6 (6 a 8 cm de diâmetro).

Todos os híbridos, com exceção do Zarco, foram classificados na categoria Extra. O híbrido Zarco, em conseqüência da quantidade de frutos tortos apresentada, foi classificado na Categoria I.

De modo geral, a produtividade de pimentão em ambiente protegido, utilizando fibra da casca de coco e fertirrigação, neste experimento, foi muito expressiva, porém há uma carência de informações na literatura sobre este sistema de cultivo.

Portanto, faz-se necessário que novos estudos sobre o assunto sejam realizados, como, por exemplo, a curva de crescimento, a marcha de acúmulo de nutrientes, o sistema de condução com diferentes números de hastes, os diferentes espaçamentos entre os vasos, dentre outros.

Com base nos resultados obtidos, pode-se concluir que os híbridos CLXP 1463, Eppo e Matador se mostraram promissores, com produtividades comerciais de 107,61 ; 102,62 e 95,31 ha $^{-1}$, respectivamente. Os híbridos CLXP 1463, Eppo, Línea e Matador apresentaram toda a pro- dução classificada como Extra.

\section{AGRADECIMENTOS}

Agradecemos à FAPESP pela concessão de bolsa de iniciação científica (Processo $n^{\circ}$ 04/03146-7) ao primeiro autor do trabalho.

\section{REFERÊNCIAS}

CARRIJO OA; VIDAL MC; REIS NVB; SOUZA RB; MAKISHIMA N. 2004. Produtividade do tomateiro em diferentes substratos e modelos de casas de vegetação. Horticultura Brasileira 22: 5-9.

FACTOR TL. 2003. Utilização do efluente de biodigestor no cultivo de pimentão em substratos, sob ambiente protegido. Jaboticabal: UNESP-FCAV. 88 f. (Tese mestrado).

FONTES PCR; DIAS EN; SILVA DJH. 2005. Dinâmica do crescimento, distribuição de matéria seca na planta e produção de pimentão em ambiente protegido. Horticultura Brasileira 23: 94-99.

FRIZZONE JA; GONÇALVES ACA; REZENDE R. 2005. Produtividade do pimentão amarelo, Capsicum annum L., cultivado em ambiente protegido em função do potencial mátrico de água no solo. Acta Scientiarum 23: 1111-1116.

MARCHIZELI SFB; YAÑEZ LD; COSTA CP. 2003, 01 de dezembro. Deu oídio (resumo): Disponível em http:// revistacultivar.1ocaweb.com.br/hf/ artigo.asp?no $=484$.

PEREIRA EC. 1995. Avaliação do crescimento e da produtividade de pimentão amarelo (Capsicum annum L.) sob diferentes potenciais matriciais de água no solo, em condições de casa de vegetação. Botucatu: UNESP-FCA. 61p. (Tese mestrado).

QUEIROGA RCF; NOGUEIRA ICC; BOTELHO NETO F; MOURA ARB; PEDROSA JF. 2002. Utilização de diferentes materiais como cobertura morta do solo no cultivo de pimentão. Horticultura 
Brasileira 20: 416-418.

RIBEIRO LG; LOPES JC; MARTINS FILHO S; RAMALHO SS. 2000. Adubação orgânica na produção do pimentão. Horticultura Brasileira 18: 134-37.

ROCHA MC; CARMO MGF; FERNANDES MCA; COSTA ESP; MANERA TC; GEDDA AEC; COELHO AA. 2004. Características químicas de frutos de pimentão de três cultivares pulverizadas com biofertilizante Agrobio e Oxicloreto de cobre. In: CONGRESSO BRASILEIRO DE OLERICULTURA, 44. Resumos... Campo
Grande: SOB (CD-ROM).

ROSA JA. 1995. Efeito da lâmina de água sobre a produção de pimentão amarelo em estufa plástica. Horticultura Brasileira 13: 110.

SÃO PAULO (Estado). 1998. Secretaria de Agricultura e Abastecimento. Programa Paulista para a melhoria dos padrões comerciais e embalagens de hortifrutigranjeiros. Classificação de pimentão. São Paulo (não paginado).

SILVA EC; RABELLO TM; MACIEL GM. 2005a, 25 de setembro. Avaliação de cultivares de pimentão em cultivo protegido no sistema hidropônico (NFT). Disponível em http://www.unifenas.br/neol/pdfs/ pimentaohidr.pdf.

SILVA EC; SCHOMOLZER IP; MACIEL GM. 2005b, 25 de setembro. Avaliação de cultivares de pimentão em ambiente protegido no solo. Disponível em http:// www.unifenas.br/neol/pdfs/pimentaoo.pdf.

TRANI PE; CARRIJO OA. 2004. Fertirrigação em hortaliças. Campinas: IAC. 53 p. 